Neth. J. Agric. Sci., 16 (1968) : 177-185

\title{
Agricultural control measures against intestinal parasites in cattle
}

\author{
D. Oostendorp and H. E. Harmsen
}

Research and Advisory Institute for Field Crops and Grassland Husbandry, Wageningen, The Netherlands

Received 15 May, 1968

\section{Summary}

In a grazing experiment with calves in 1967 the effect of various practical measures was investigated on the development of worm infestation of the alimentary tract and on the liveweight gain of calves. Groups of 12 bull calves each were used, born in February and put to pasture in May. By that time the animals had been castrated, dehorned and vaccinated against lungworm. In the control group, grazing previously grazed pastures serious parasitic gastroenteritis occurred; three animals died as a result.

Mowing the first cut and normal rotational grazing afterwards hardly showed any better results in liveweight gain of the calves. In this group one calf died as a result of parasitic gastroenteritis.

As in previous years the only effective method to obtain good gains as well as to keep worm infection of the alimentary tract at a low and harmless level, was systematic grazing on aftermath.

By supplying $1 \mathrm{~kg}$ concentrates additionally compared to the control group, $2 \mathrm{~kg}$ concentrates in total, gains of the calves improved as we!l. In this case with normal rotational grazing, worm infection of the alimentary tract attained dangerously high levels, unlike the trend in the group grazing on aftermath without concentrates. In this group worm infection remained on a low and harmless level throughout the season. A preventive treatment with thiabendazole barred deaths, but only slightly improved gains compared to the control group.

To gain some information on the applicability of systematic grazing of calves on aftermath in the farm management programme, in 1967 this system was applied on 50 practical farms and 5 farm units of the 'C.R. Waiboerhoeve'. It was found to be quite feasible to allow the calves to graze exclusively on aftermath on these farms. Of the 688 calves involved in this investigation the average liveweight gain was 779 $\mathrm{g} / \mathrm{a} / \mathrm{d}$ during the grazing season.

\section{Introduction}

On a great many farms the rearing of calves at pasture has been a source of deep concern every year. The main cause of this is infestation of lungworms and worms in the alimentary tract.

For many years the object has been to find a farm management approach that will keep these infestations at a harmless level. In this relation much was made of calves 
kept on a rotational grazing system. Until recently, however, results have been disappointing. In advising too much emphasis was laid on the minimum development period from egg to infective larvae, which is $4-6$ days at $25^{\circ} \mathrm{C}$, and too little account was taken of the development period of the main body of larvae, often being much longer (Kloosterman, 1968). In normal rotational grazing the calves return to the pasture already grazed by them after 3-5 weeks and this may coincide with the presence of a considerable number of infective larvae. Even after a longer period grazing may be risky, because longevity of the worms is at least one year and therefore throughout the grazing period (Rose, 1961, 1963, 1966; Williams, 1965; Donald, 1967; Kutzer, 1967). Of course all this depends on the weather conditions.

The question arose whether a farm management approach could be developed guaranteeing a natural balance between parasite and host. In order to gain some information on this subject, a series of experiments was started on the experimental farm 'De Vlierd' in 1962, in which the effects of various preventive measures were tested by the growth rate of calves. These experiments were set up in co-operation with Prof. Dr. D. Swierstra of the Institute of Veterinary Parasitology and Parasitic Diseases at Utrecht. In the first instance the object of the experiments was to test the following measures: (a) grazing newly sown leys; (b) feeding grass with loose housing; (c) grazing on aftermath.

On theoretical grounds favourable effects were to be expected of each of these measures. In grazing newly sown leys the low initial level of infection is emphasized; in loose housing the control is based on interrupting the life cycle of the worms, viz. by preventing the direct return of faeces to the pasture; in grazing on aftermath the risk of infection is decreased, because part of the larvae is removed with the grass mown. Disturbing the faecal pats and the short stubble have an adverse effect on the environment of the remaining larvae. Any infection left of the last season is also much reduced by mowing the first cut. The interval between two subsequent grazings of the same field is lengthened by 4 to 6 weeks.

Application of each of these measures tested offered good prospects (Oostendorp, 1965; Oostendorp, Harmsen and Westra, 1965). Which method should be applied in a special case depends closely on the farming conditions. When newly sown leys are regularly available, or cattle are already kept in loose houses (e.g. zero grazing), it is, of course, advantageous to allow the calves to profit of these systems with slight risks of parasitic infection.

Farms, however, which can turn to account leys or a loosehousing system (measures 1 and 2) are an exception under Dutch conditions. Measure 3, i.e. grazing fields of which the previous cut is mown, is of much greater practical importance. Since this system could be applied on almost all Dutch cattle farms, development of the method was specially emphasized in the investigation. In 1964, 1965 and 1966 liveweight gains with this grazing system and supplementary feeding of $2 \mathrm{~kg}$ of concentrates per day were 762,847 and 839 gram per animal per day $(\mathrm{g} / \mathrm{a} / \mathrm{d})$ respectively, during the grazing period. In addition to the effect on any developing worm infections, or may be even due to, a favourable effect was found on the necessary supplementary feeding. Whereas in normal rotational grazing $2 \mathrm{~kg}$ of concentrates frequently was found to be insuffient to prevent serious worm infection, in 1965 and 1966 in grazing mown grassland with $2 \mathrm{~kg}$ concentrates as supplementary feed, liveweight gains were 847 and $839 \mathrm{~g} / \mathrm{a} / \mathrm{d}$ resp., and with $1 \mathrm{~kg}$ concentrates 719 and $751 \mathrm{~g} / \mathrm{a} / \mathrm{d}$ respectively. The liveweight gains achieved by this grazing management with only $1 \mathrm{~kg}$ concentrates clearly were very satisfactory as well. 


\section{Lay-out of the comparative experiments on 'De Vlierd'}

In the 1967-investigation on 'De Vlierd' the following factors were emphasized: (a) grassland management; (b) feeding level; (c) preventive use of anthelmintics.

As in the preceding years groups of 12 bull calves were used, born in February and put to pasture during May. On 14 February 100 new-born bull calves were bought and reared during the first two months on $25 \mathrm{~kg}$ of artificial milk, $2 \mathrm{~kg}$ concentrates per day at a maximum and ad lib. hay and water. On 16 March the animals were dehorned, on 21 March and 18 April lungworm vaccine was applied and on 18 May 72 calves, intended for the experiment on parasitic infections, were castrated. The other calves were not castrated, because they were used in an experiment on bull fattening at pasture.

There were no difficulties during rearing. No animals were lost. The average weight increase of the castrated animals was $671 \mathrm{~g} / \mathrm{a} / \mathrm{d}$ in the period from 2 March to 28 April. On 28 April 6 experimental groups were formed of 12 animals each. The following treatments were applied:

A. control, viz. rotational grazing without cutting, $1 \mathrm{~kg}$ concentrates;

B. rotational grazing without cutting, $1 \mathrm{~kg}$ concentrates, thiabendazole on $1 / 6,1 / 8$ an $6 / 9$;

C. rotational grazing with the first cut mown, $1 \mathrm{~kg}$ concentrates;

D. rotational grazing on aftermath, $1 \mathrm{~kg}$ concentrates;

E. rotational grazing on aftermath, $0 \mathrm{~kg}$ concentrates;

F. rotational grazing without cutting, $2 \mathrm{~kg}$ concentrates.

The groups A, B, C and F each grazed 1 ha of grassland, subdivided into 4 fields. The groups were rotationally grazed at the same rate on these fields. To have cut fields continuously available, the groups $D$ and $E$ were allowed to graze double this area, viz. 2 ha sub-divided into 8 fields. The fields grazed by the groups A, B and F were consistently not cut. Excess grass in May and June was removed by allowing $11 / 2$-year old bullocks to graze a number of fields in these treatments. All groups grazed pastures managed in the same way since 1962, i.e. the group vaccinated with thiabendazole, grazed e.g. fields on which preventive phenothiazine and thiabendazole had been applied in the previous years. In 1966 the level of infection was, however, very low and there was hardly any difference in level between the various treatments. Presumably, this was the result of excess grass on all treatments being cut that year and due to abundant growth this occurred rather frequently. It may therefore be assumed that at the beginning of the experiment in 1967 , there were no differences in the level of infection between the various treatments.

The groups $A, B$ and $F$ were put to pasture on 3 May, the groups $C, D$ and $E$ on 17 May.

Thiabendazole was applied in concentrate pellets (Bovizole) as a group treatment. According to prescription $88 \mathrm{mg}$ of thiabendazole was applied per $\mathrm{kg}$ liveweight. Due care was taken that bovizole was indeed taken in by all animals. From 17 May onwards, every two weeks faecal samples were taken of 5 animals per group for egg counts. The egg counts were carried out by the Institute of Veterinary Parasitology and Parasitic Diseases at Utrecht. 


\section{Results of the comparative experiments on 'De Vlierd'}

Effect of grassland management (Fig. 1)

Serious parasitic gastroenteritis occurred in the control group A. Liveweight gains of the calves in June, July and August were slight and even negative in September. A light recovery occurred in October. Three calves died suffering from parasitic gastroenteritis on $18 / 8,5 / 9$ and $8 / 9$ respectively. Average liveweight gain of the remaining calves was $456 \mathrm{~g} / \mathrm{a} / \mathrm{d}$ during the period 28 April to 18 October. The number of eggs per gram of faeces (e.p.g-number) increased to an average 1024 in June. In July the average decreased gradually to 178. At the end of August another increase occurred, but during September and October the average level remained at about 200. Consequently, egg passing attained a clear top at the end of June. This corresponds with observations of Bürger et al. (1966). Analysis showed that in the experiment of Bürger this top was mainly formed by Cooperia and to a much less extent by Ostertagia. Decreased egg passing after June, presumably was due to a developing resistance to Cooperia, i.a. expressed by decreased egg production. In any case, Cooperia and Ostertagia were also the most frequently occurring species on 'De Vlierd'.

In England Michel (1966) obtained very good results with Ostertagia-infected calves by putting them on aftermath about $15 \mathrm{July}$ and treating them with an anthelminthic at the same moment.

Under the experimental conditions on 'De Vlierd' a similar method would probably have been less effective, because here the calves were already seriously infected in June and as a result growth was already retarded.

Mowing the first cut with normal rotational grazing afterwards on previously grazed pasture, only slightly improved the gain of the calves. The growth curve is very much like that of the control group. In this group one calf died from parasitic gastroenteritis on $22 / 9$. The average liveweight gain of the remaining calves was $509 \mathrm{~g} / \mathrm{a} / \mathrm{d}$ during the period 28 April to 18 October.

Because the calves were put at pasture a fortnight later, the increase in e.p.g-number occurred somewhat later, while the top remained far below that of the control group In July and August, however, the e.p.g-number remained rather high. This group
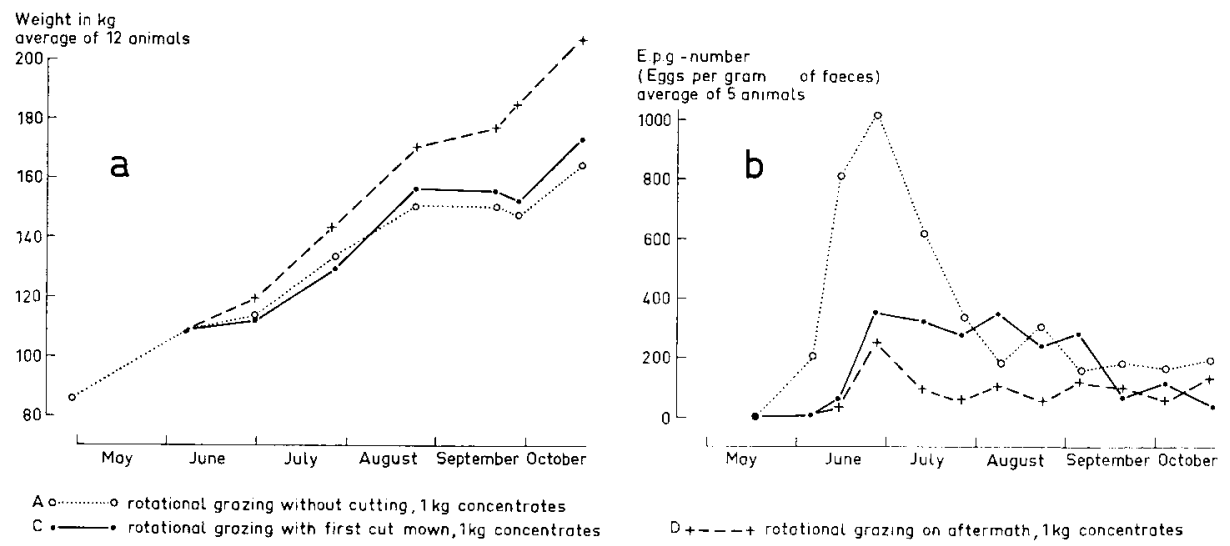

Fig. 1 Effect of grassland management on growth (a) and on e.p.g-number (b) 
showed low e.p.g-numbers only in September and October.

Whereas mowing the first cut obviously was insufficient to keep a worm infection at a harmless level, like in previous years, systematic grazing of calves on aftermath proved to be a very efficient method to guarantee good gains as well as to keep worm infection of the alimentary tract at a low and harmless level. The average liveweight gain of this group was $705 \mathrm{~g} / \mathrm{a} / \mathrm{d}$ during the period 28 April to $18 \mathrm{Oc}$ tober. This group showed an e.p.g-number of 248 at the end of June. During the further season the e.p.g-number of this group was about 100 .

\section{Effect of feeding (Fig. 2)}

The calves in the control group received $1 \mathrm{~kg}$ concentrates per day. By an additional supply of $1 \mathrm{~kg}$ concentrates, in total $2 \mathrm{~kg}$, considerably improved liveweight gains were obtained. This improvement mainly occurred in the first part of the grazing season. In September and October the gain of this group was clearly retarded compared to the group grazing on aftermath without supplementary feeding. The result was that liveweights of both groups were the same again on 18 October. The average gain of these two groups was $641 \mathrm{~g} / \mathrm{a} / \mathrm{d}$ during the period 28 April to 18 October.

The additional supply of $1 \mathrm{~kg}$ concentrates decreased the e.p.g-number considerably and the top was at 516 at the end of June. This group showed a clear secondary top in the e.p.g curve at the beginning of September (e.p.g-number 404). Despite supplementary feeding of $2 \mathrm{~kg}$ concentrates the worm infection of the alimentary tract increased to a dangerously high level, unlike the results of the group grazing on aftermath without supplementary feed. The e.p.g-number of the latter group remained at a specially low and harmless level throughout the grazing season.

As a result of the appreciable difference in supplementary feed, the group without concentrates retarded in liveweight gain during May and June. The calves, however, looked completely healthy throughout the grazing season. In August, September and October, when the grass intake of these calves evidently increased, the low level of infection was clearly expressed by the appreciably higher liveweight gains in this group compared to those in the seriously infected group with normal rotational grazing and $2 \mathrm{~kg}$ concentrates.
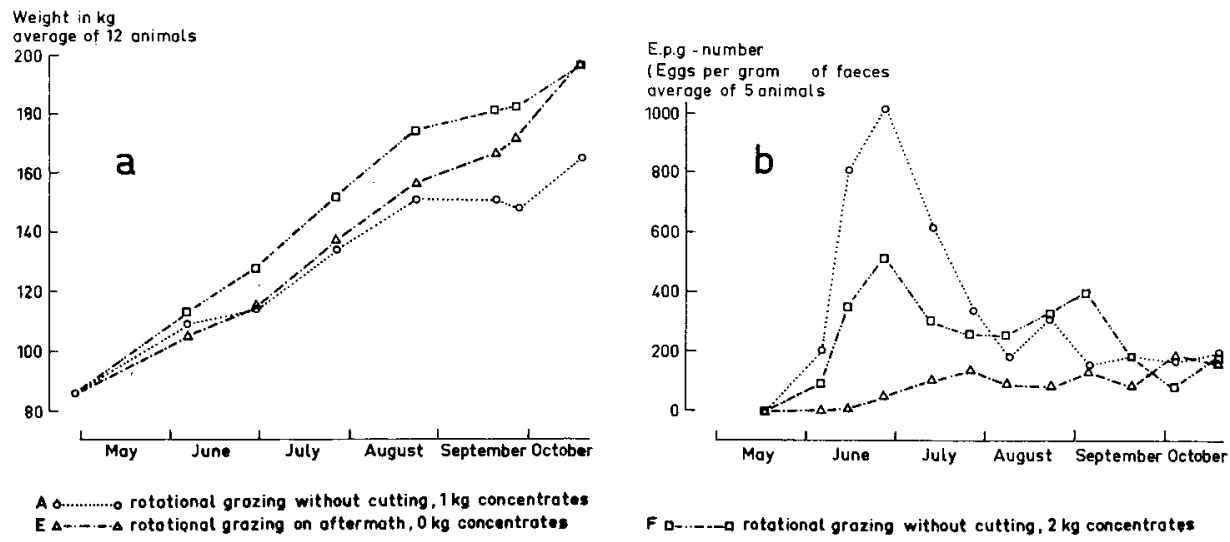

Fig. 2 Effect of feeding on growth (a) and on e.p.g-number (b) 


\section{Effect of anthelmintic (Fig. 3)}

A preventive dose of thiabendazole (Bovizole) was applied on $1 / 6,1 / 8$ and $6 / 9$. In this treatment death cases did not occur, but only slightly improved liveweight gains were obtained compared to the control group. Especially in August and September liveweight gains were inadequate. The average gain was $520 \mathrm{~g} / \mathrm{a} / \mathrm{d}$ during the period 28 April to 18 October.

Worm infection, however, showed a completely different trend from that in the control group. As a result of treatment with thiabendazole the infection level remained low until the end of August. In September worm infection suddenly increased to an e.p.g-number of 494 . The routine treatment at the beginning of September apparently had been insufficient to withstand the heavy infection pressure of that moment. The latter was probably caused by heavy rainfall after a long period of drought. On 'De Vlierd' there was only 25 and $34 \mathrm{~mm}$ of rain in June and July resp. After this period of drought the weather changed on 13 August and a period with much rainfall started, in total $89 \mathrm{~mm}$ in the rest of August. As a result of this change in the weather a great number of larvae, whose development had been retarded during the drought period, probably developed into infective larvae in the second half of August and thus the calves had to cope with a very heavy infection during this period. Various other workers found similar break-outs of worm infection after drought (Durie, 1961, 1962; Rose, 1962, 1964 and Kutzer, 1967).
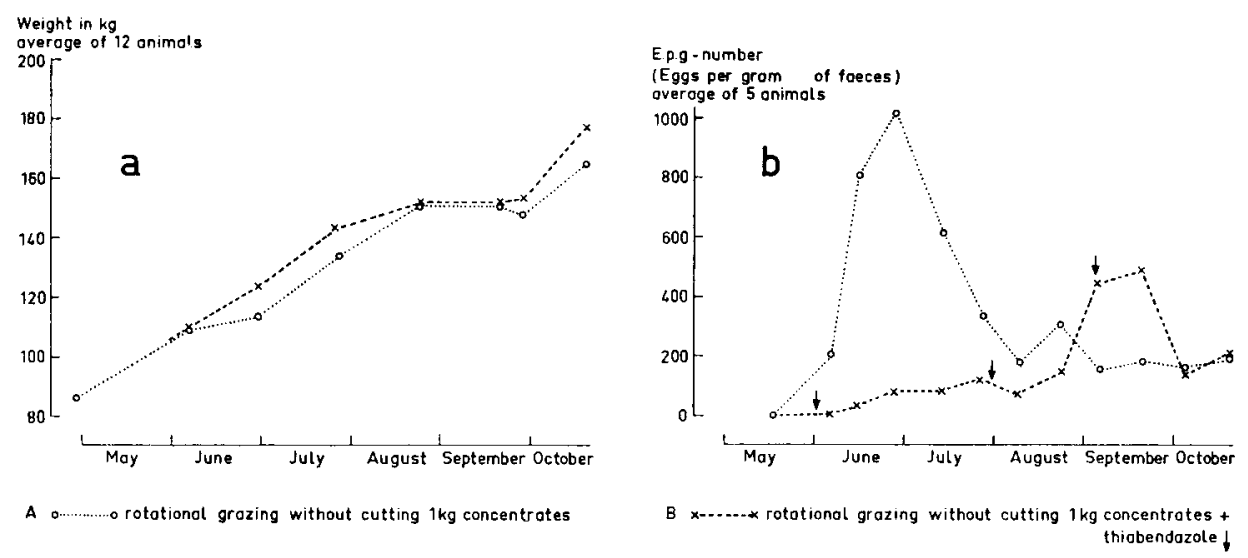

Fig. 3 Effect of anthelmintic on growth (a) and on e.p.g-number (b)

\section{Experiments on a practical scale on farms}

In comparative experiments as carried out on 'De Vlierd', the question remains whether a certain system can be adjusted to a farming programme and whether it has any effect on the other items of the programme. To gain some information on the applicability of grazing of calves on aftermath, in 1966 this system was applied on six practical farms in the province of Utrecht and on five farm units of the 'C.R. Waiboerhoeve' (Oostendorp and Harmsen, 1967).

Since this was quite successful, the number of practical farms involved in this investigation was increased to 50 throughout the country. Farms were selected which 
had special difficulties with worm infections, when rearing calves in the previous years. This research was carried out in co-operation with the agricultural advisory service in the scope of inter-provincial research (series 751).

On these farms calves were allowed to graze aftermath almost exclusively. The old system of grazing the calves on permanent calf pastures that were not mown in the season was dropped and changed into grazing on normal grassland fields. These fields sometimes were sub-divided once or more times to allow a more adequate rotational grazing system. With a view to adequate grass supply the object was not to allow the animals to graze a plot longer than a fortnight. Supplementary feeding of calves at pasture with milk and milk products was also dropped, because it was troublesome to transport this milk to the various pastures. Concentrates were therefore exclusively supplied, about $11 / 2 \mathrm{~kg}$ per day. The concentrates were supplied to the calves in group feeding. The risk in this system is that the intake of concentrates of the older calves might be larger than that of the younger ones and for this reason the liveweight gains of the various age groups was investigated (see Table 1).

Table 1 Liveweight gain of calves in group feeding of concentrates

\begin{tabular}{lccccccc}
\hline Born & Before January & January & February & March & April & May & Total \\
Number of calves & 86 & 75 & 153 & 181 & 74 & 19 & 776 \\
Gain (g/a/d) & 795 & 839 & 803 & 767 & 698 & 624 & $588^{1}$
\end{tabular}

175 bull calves born in February and 25 calves which were housed during the summer have been left out of consideration

It was found that the liveweight gains of the calves, born before January up to and including those in March, showed gains of about $800 \mathrm{~g} / \mathrm{a} / \mathrm{d}$ in all age groups. The calves born in April and May do show a somewhat lower, though still satisfactory, gain for this age group.

In a grazing system, in which good grass supply is specially emphasized, the concentrates may be fed to the calves in group feeding without difficulties. The average liveweight gain of the 688 calves involved in this investigation was $779 \mathrm{~g} / \mathrm{a} / \mathrm{d}$ during the grazing period.

With $1 \frac{1}{2} \mathrm{~kg}$ concentrates this gain may be considered very satisfactory. This the more so, because in the previous years liveweight gains of the calves were very poor on these farms and many animals died as a result of worm infection.

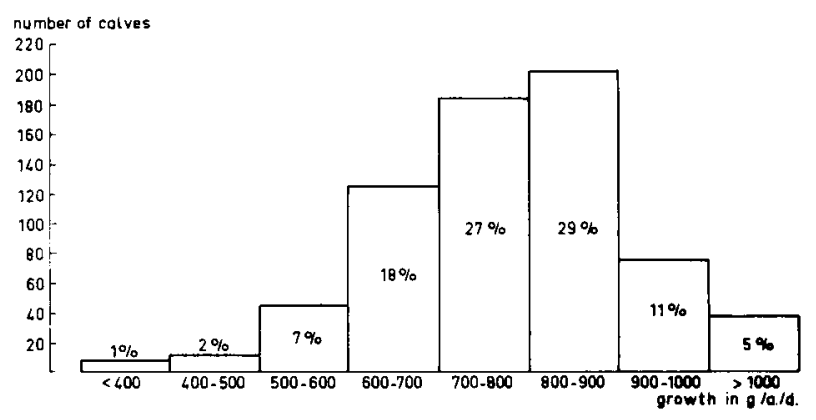

Fig. 4 Frequency distribution of the growth of the calves; in total 688 heads (series 751-1967). Growth average 779 g/animal/ day 
The frequency distribution of the liveweight gains of the calves has been shown in Fig. 4; $92 \%$ of the calves was in the liveweight-gain class between 500 and 1000 $\mathrm{g} / \mathrm{a} / \mathrm{d} ; 3 \%$ gained less than $500 \mathrm{~g} / \mathrm{a} / \mathrm{d}$, because of various diseases. The $5 \%$ gaining over $1000 \mathrm{~g} / \mathrm{a} / \mathrm{d}$, concerned mainly bull calves retained on a number of farms and sometimes receiving some extra supplementary feed.

Worm infection of the calves was checked by analysis of the faeces, taking place four time per season. The analysis was carried out by ir. A. Kloosterman of the Department of Animal Husbandry of the Agricultural University at Wageningen, Fig. 5 shows the results of these analysis.
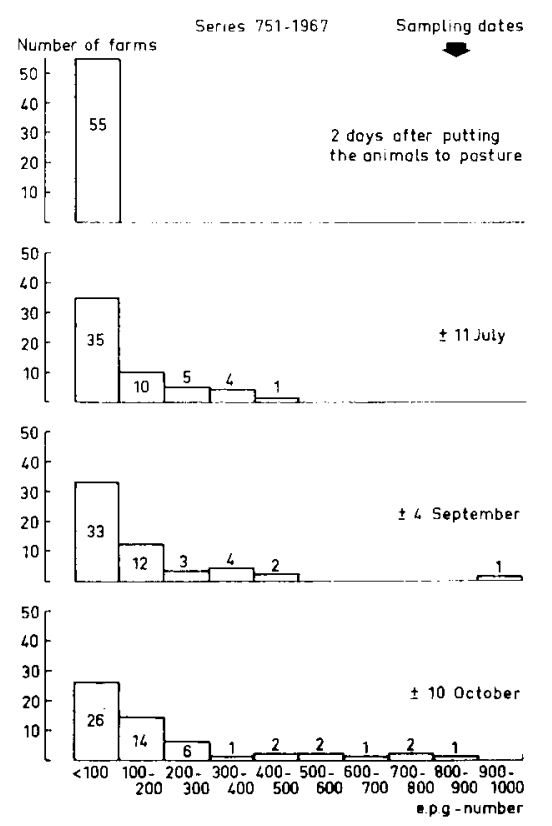

Fig. 5 Frequency distribution of the e.p.g-number on 55 farms

Two days after putting the calves to pasture almost all samples were negative. Later in the season a number of farms showed a high level of worm infection. These were mainly farms which due to the dry summer, could not always meet the condition of grazing on aftermath, and these showed a too high level of worm infection in autumn. Forty farms out of 55 were successful in keeping the level of infection on a low and harmless level by allowing the calves to graze on aftermath.

\section{Conclusions}

In experiments on the experimental farm 'De Vlierd' it was found that grazing on aftermath was a very effective method to keep worm infections of the alimentary tract at a low and harmless level. Even without supplementary feeding good liveweight gains were obtained, so that this method will enable healthy and cheap rearing of calves. 
Exclusive supply of additional feeding or application of a preventive dose of anthelmintic only had a price increasing effect, decreasing even the chance of a reasonable result.

Moreover, these methods do not offer a long-term solution of the problem, because the root of the trouble is not taken away. This is indeed the case when grassland management is changed to systematic grazing on aftermath. In applying this system on 55 practical farms it was found that this could also be successfully fitted into the farming programme.

\section{References}

Bürger, H. J., Eckert, J., Wetzel, H. and Michael, S.A., 1966. Zur Epizootologie des Trichostrongyliden-Befalles des Rindes in Nordwestdeutschland. Dtsch. tierärztl. Wschr., 15 Oktober: 503.

Donald, A. D., 1967. Populations of strongyloid infective larvae in pastures after sheep are removed from grazing. Aust. Vet. J., $43: 122$.

Durie, P. H., 1961. Parasitic gastro-enteritis of cattle: The distribution and survival of infective strongyle larvae on pasture. Aust. J. agric. Res., 12: 1200.

Durie, P. H., 1962. Parasitic gastro-enteritis of cattle: Seasonal fluctuations in populations of strongyle larvae on a calf pasture and their significance in infection of the grazing animal. Aust. J. agric. Res., $13: 767$.

Kloosterman, A., 1968. De epidemiologie van maagdarmwormen bij runderen. Veeteelt- en Zuivelberichten (in press).

Kutzer, E., 1967. Biologie und Oekologie der präparasitären. Entwicklungsstadien von Ostertagia ostertagi und Cooperia oncophora (Nematoda, Trichostrongylidae) im Hinblick auf die Epidemiologie der Trichostrongylidose der Rinder. Wiener tierärztl. Mschr., 54: 164.

Michel, J., 1966. The epidemiology and control of parasitic gastro-enteritis in calves. IV Intern. Tagung Weltgesellsch. Buiatrik, Zürich.

Oostendorp, D., 1965. Worm infestation in calves fed on grass. Grassland Research Institute, Hurley, Technical Report nr. 1: 13.

Oostendorp, D., Harmsen, H. E. and Westera, A., 1965. Worminfecties bij kalveren in de weide. Proefstation voor de Akker- en Weidebouw, Wageningen, Publikatie nr. $27: 34$.

Oostendorp, D. and Harmsen, H. E., 1967. Beweidingsmaatregelen tegen maagdarmwormen bij kalveren. Proefstation voor de Akker- en Weidebouw, Wageningen, Mededeling nr. 132.

Rose, J. H., 1961. Some observations on the free living stages of Ostertagia ostertagi, a stomach worm of cattle. Parasitology, 51: 295.

Rose, J. H., 1962. Further observations on the free-living stages of Ostertagia ostertagi in cattle. J. Comp. Path., $72: 11$.

Rose, J. H., 1963. Ecological observations and laboratory experiments on the free living stages of Cooperia oncophora. J. Comp. Path., 73: 285.

Rose, J. H., 1963. Observations on the free-living stages of the stomach worm Haemonchus contortus. Parasitology, 53: 469.

Rose, J. H., 1964. Relationship between environment and the development and migration of the free-living stages of Haemonchus contortus. J. Comp. Path., $74: 163$.

Rose, J. H., 1966. Investigations into the free-living phase of the life-cycle of Nematodirus helvetianus. Parasitology, 56:679.

Williams, J. C., 1965. Survival of cattle parasites on pasture. Louisiana Agric., $8: 10$. 